\section{May Soil Solarization Reduce the Juvenile Period in Olive?}

\author{
Milad El Riachy ${ }^{1}$ \\ Lebanese Agricultural Research Institute, Laboratory of Olive Oil, P.O. Box \\ 287-Zahle, Tal Amara, Bekaa, Lebanon
}

Luis Rallo

Departamento de Agronomía, Universidad de Córdoba, Campus de Rabanales, Edificio Celestino Mutis, Carretera Madrid-Cádiz, Km 396, E-14014 Córdoba, Spain

Raúl de la Rosa and Lorenzo León
IFAPA Centro 'Alameda del Obispo,' Avda. Menéndez Pidal, s/n, E-14004
Córdoba, Spain

Additional index words. Olea europaea, breeding, flowering, olive seedlings

\begin{abstract}
The duration of the juvenile period (JP) before the seedlings reach the adult phase (AP) and begin flowering is the major impediment for fruit breeding in olive. In this work, the effect of soil solarization on the growth and duration of the JP of olive seedlings was studied. Seedlings obtained from open pollination of 'Manzanilla de Sevilla' and from crosses between 'Arbequina' $\times$ 'Arbosana' and 'Picual' $\times$ 'Koroneiki' were tested. Solarization treatment consisted on covering the soil around the trees for 3 years by black plastic film in a split-plot design with the three progenies as the main factor and solarization/not solarization as the secondary factor. Solarization resulted in both higher soil temperature and soil moisture in solarized plots with respect to non-solarized. Significant differences between crosses were found for plant vigor and flowering measurements throughout the experiment. Soil solarization increased trunk diameter and the number of seedlings reaching AP in 'Manzanilla' open progeny. A positive effect of solarization on flowering index was also observed in 'Picual' $\times$ 'Koroneiki' progenies. These results suggest that soil solarization may be recommended as a tool for shortening the duration of the JP and thus accelerating the selection process in olive breeding programs.
\end{abstract}

Juvenile period is defined as the time during which a seedling cannot achieve and sustain the capacity or potential to flower. This period can persist up to 30 to 40 years in some fruit species (Hackett, 1985). In olive (Olea europaea L.), JP can reach up to 13 years under natural growing conditions (Bellini, 1993). This long period is the main reason for the scarcity of new olive varieties generated by olive breeding programs in comparison with other fruit species (Barranco and Rallo, 2006).

In fruit trees, the duration of the JP is somehow affected by the genotype of the seedling (Santos-Antunes et al., 2005), by the environment in which it grows (Visser, 1970), and by the agricultural practices used (Bagnall, 1992; Hackett, 1985; Zimmerman, 1973). In fact, it has been observed that the duration of JP is inversely related to the vigor of the seedlings (Dennis, 1968). In particular, the percentage of seedlings with short JP increases with the diameter (Visser, 1970) and the

Received for publication 6 May 2011. Accepted for publication 12 July 2011.

This research was partly funded by Project AGR-649 of the Consejería de Innovación, Ciencia y Empresa (Junta de Andalucía).

${ }^{1}$ To whom reprint requests should be addressed; e-mail mriachy@lari.gov.lb. mine if the use of this technique can be recommended in olive breeding programs.

\section{Materials and Methods}

Plant material. Seedlings from open pollination of the cultivar Manzanilla de Sevilla and from crosses between the cultivars Arbequina $\times$ Arbosana and Picual $\times$ Koroneiki were tested. These seedlings were generated following the standard procedures used in the olive breeding program carried out in Córdoba since 1991 (Santos-Antunes et al., 2005). The crosses were made in Spring 2004, seeds were germinated in November, and growth of the obtained plants was forced in a greenhouse until Mar. 2006, when they were transplanted into the field. Trees were planted at a distance of $4 \mathrm{~m}$ between rows and $1.5 \mathrm{~m}$ within row, were tied and pruned to $1-\mathrm{m}$ height, and allowed to develop the canopy freely from that height. Drip irrigation with $\approx 1500 \mathrm{~m}^{3} \cdot \mathrm{ha}^{-1} \cdot$ year $^{-1}$ water was applied from May to September as gauged by rainfall and evapotranspiration. The experimental trial was located in Córdoba, southern Spain, in an area characterized by a subtropical Mediterranean climate in a soil formed by fluvial deposits with sufficient depth.

Plastic film installation. Before applying the plastic film, the soil was well prepared (free of weeds and with the smoothest surface possible). In June 2006, and just after irrigation to field capacity, the ground around the tree was covered with a black polythene sheet $3 \mathrm{~m}$ wide and $150 \mu \mathrm{m}$ thick. The plastic film was placed in a central position along the planting line. The plastic film was well stretched and all edges were covered by ground to avoid any air penetration, which would reduce temperature and dry the ground. Each solarized subplot of $\approx 22 \mathrm{~m}^{2}$ was covered by plastic film.

Temperature and moisture measurement. Two 'Watermark' automatic monitors (Irrometer Company, Riverside, CA) were placed in the field, each one in the middle of two treatments (solarized and not solarized). Eight sensors were connected to each monitor distributed as follows: two temperature and two moisture sensors at $20-$ and $40-\mathrm{cm}$ depth, respectively, located in the central area of two subplots (solarized and not solarized) adjacent to each monitor.

WDDL-3667 (Spectrum Technologies, Inc., Plainfield, IL) sensors with a measurement range of -30 to $100^{\circ} \mathrm{C}$ and 'Watermark' SENW5SS (Spectrum Technologies, Inc.) sensors with a 0 - to 200 -cbars measurement range were used for monitoring soil temperature and moisture, respectively. 'Watermark' sensors are of granular matrix, electrical resistance type, suitable for almost all kinds of soils.

'Watergraph' software was used for collecting information and programmed to record data at 15 -min intervals.

Growth and flowering measurements. Growth was assessed by measuring the height and trunk diameter of the seedlings every 2 months during the first year (July 2006 to May 2007). Additional measurements of height and trunk diameter were made during winter 
dormancy of the next 2 years (Jan. 2008 and Jan. 2009).

The presence of flowers as an indicator of phase change was evaluated in the different genotypes in the two treatments in May 2008 and May 2009. A flowering index was also recorded in 2009 based on a qualitative scale from 0 to 3 per tree and the average index for the six trees of any subplot was calculated $(0=$ no flowering, $1=$ low flowering, 2 = medium flowering, and $3=$ plenty of flowering).

Experimental design and statistical analysis. The experiment was conducted in a split-plot design with three crosses as the main factor and solarization/no solarization as the secondary factor. The experiment included eight blocks with six trees per subplot and 18 trees per plot. Data were analyzed using the Statistix 8 software (Analytica Software, Tallahassee, FL). Analysis of variance was performed to test the effect of crosses and of soil solarization, and means comparison was carried out using least significant difference at the 0.05 rejection level.

\section{Results and Discussion}

Soil temperature and moisture. Soil temperature was higher in solarized soils than non-solarized soils throughout the year. The
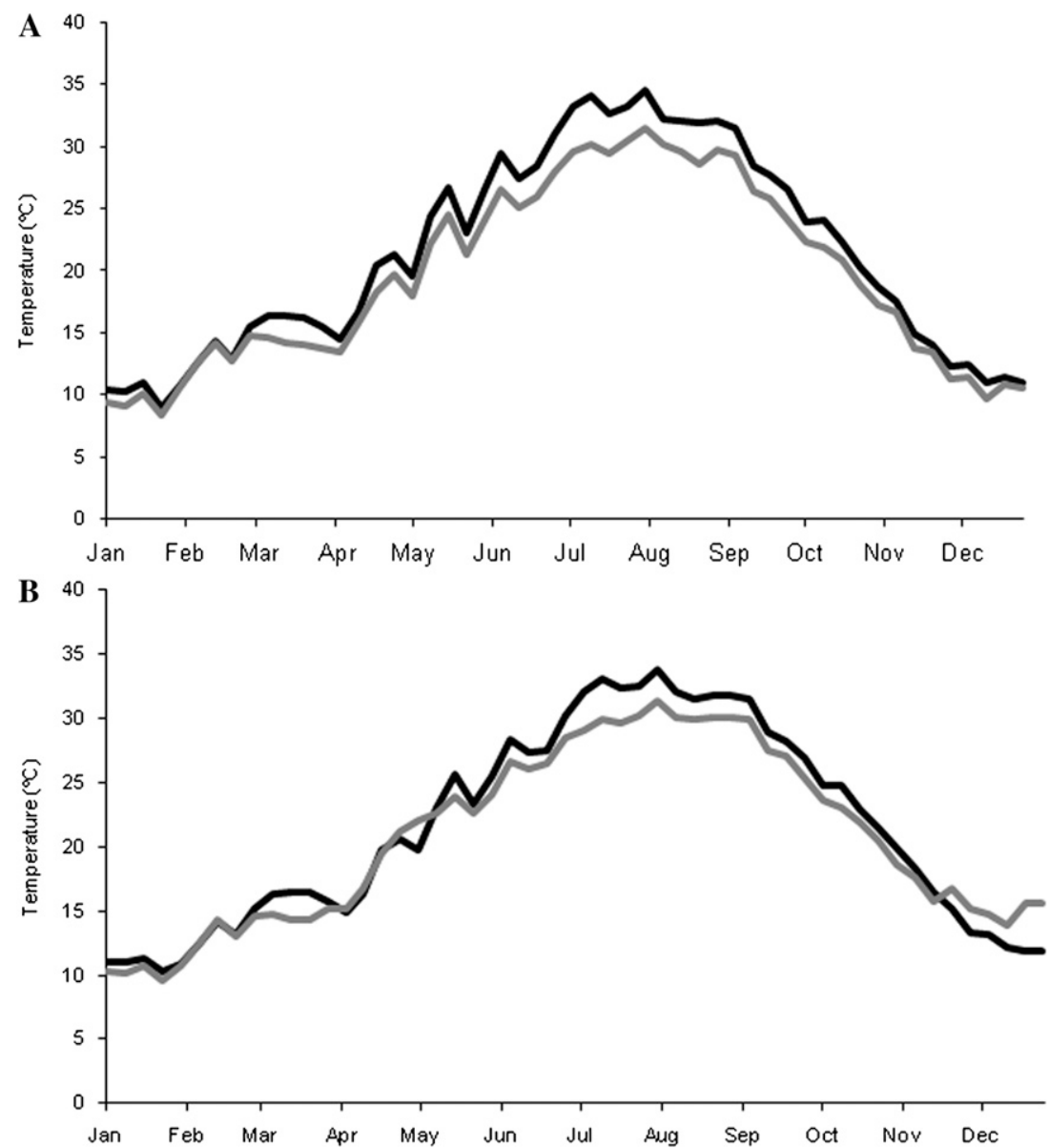

Fig. 1. Soil temperature in solarized (black) and in not solarized soils (gray) at 20-cm (up) and at 40-cm depth (down) in the first year of the experiment. average seasonal temperatures at $20 \mathrm{~cm}$ and $40 \mathrm{~cm}$ were 31.08 and $30.83{ }^{\circ} \mathrm{C}$ (Summer 2006), 18.37 and $19.19^{\circ} \mathrm{C}$ (Fall 2006), 12.72 and $13.08^{\circ} \mathrm{C}$ (Winter 2007), 22.53 and $22.07^{\circ} \mathrm{C}$ (Spring 2007), 31.57 and $31.23{ }^{\circ} \mathrm{C}$ (Summer 2007), and 17.82 and $18.66{ }^{\circ} \mathrm{C}$ (Fall 2007), respectively, in solarized soils; and 27.79 and $27.90{ }^{\circ} \mathrm{C}$ (Summer 2006), 16.96 and $17.96{ }^{\circ} \mathrm{C}$ (Fall 2006), 11.74 and $12.24{ }^{\circ} \mathrm{C}$ (Winter 2007), 20.54 and $21.59{ }^{\circ} \mathrm{C}$ (Spring 2007), 28.85 and $29.27^{\circ} \mathrm{C}$ (Summer 2007), and 16.47 and $18.88^{\circ} \mathrm{C}$ (Fall 2007), respectively, in nonsolarized soils. The temperature difference between the two treatments (solarized and non-solarized soils) was indisputable, particularly in the hottest months (from July to September) (Fig. 1). Average differences of 4 to $5{ }^{\circ} \mathrm{C}$ were usually found between solarized and non-solarized soils during that time of the year. Only during winter months non-solarized soils showed slightly higher temperatures than solarized soils, particularly at $40-\mathrm{cm}$ depth, a phenomenon previously observed in solarization studies. These results agree with those obtained by Duncan et al. (1992), who observed an average of $5{ }^{\circ} \mathrm{C}$ higher temperature at $15-\mathrm{cm}$ and $30-\mathrm{cm}$ depth in solarized soils compared with non-solarized soils. Also, these results partially agree with those obtained by Stapleton et al. (1993), who observed an average of $5{ }^{\circ} \mathrm{C}$ higher tempera- ture at $30-\mathrm{cm}$ depth and of $8{ }^{\circ} \mathrm{C}$ at $18-\mathrm{cm}$ depth.

Soil moisture was also higher in solarized soils at both depths with average values at 20- and 40-cm depth of 45.9 and 31.4 cbars, respectively, in solarized soils and 53.0 and 43.6 cbars, respectively, in non-solarized soils. In addition, after irrigation or precipitation, soil moisture trends at both depths showed higher variation in non-solarized soils, whereas in solarized soils, moisture remained more constant (Fig. 2). Moreover, in solarized soils, recorded moisture values at $40-\mathrm{cm}$ depth remained below 80 cbars (threshold of possible dangerous soil drying) and reached values higher than $80 \mathrm{cbars}$ at 20 -cm depth only in a limited number of days in March, August, and November (Fig. 2). However, in non-solarized soils, moisture values exceeded this threshold ( 80 cbars) for longer periods and reached higher values at $20-\mathrm{cm}$ (in March, middle of June to middle of September, and middle of October to middle of November) and at 40-cm depth (in March and middle of October to middle of November). These results are consistent with the findings of Stapleton and Garza-Lopez (1988) and Stapleton et al. (1993) that indicated the importance of solarization in the retention of rain and irrigation water.

Seedling growth. Significant correlation was observed between plant height and trunk diameter through the experimental period with correlation coefficients between these two measurements up to 0.72 (July 2006: $R^{2}=$ 0.35; Sept. 2006: $R^{2}=0.38$; Nov. 2006: $R^{2}=$ 0.39; Jan. 2007: $R^{2}=0.43$; Mar. 2007: $R^{2}=0.41$; May 2007: $R^{2}=0.44$; Jan. 2008: $R^{2}=0.53$; Jan 2009: $R^{2}=0.72$ ). Significant correlation between height and diameter measurements in olive seedlings has been previously reported (De la Rosa et al., 2006; Rallo et al., 2008).

Solarization produced a significant increase in trunk diameter in the first year of the experiment; however, in the next 2 years, the differences were not significant (Table 1). On the other hand, plant height did not show significant differences between solarized and not solarized soils (Table 2). Previous works with olive seedlings found no significant differences in either height or trunk diameter between solarized and non-solarized treatments (Santos-Antunes, 1999). However, Duncan et al. (1992) observed a significantly larger diameter in solarized peach trees, although the difference in height was not statistically significant. The positive influence of solarization on vegetative growth of plants has been attributed to the higher temperatures reached in solarized soils (Stapleton and DeVay, 1982), which led to an increased growth response resulting from soil disinfestation and to the increased retention of water in these soils (Duncan et al., 1992; Stapleton and Garza-Lopez, 1988).

Significant differences between crosses were found throughout the experiment for both plant height and trunk diameter. Seedlings resulting from open pollination of 'Manzanilla de Sevilla' maintained a significantly higher 
plant height and trunk diameter than the other two crosses 'Arbequina' $x$ 'Arbosana' and 'Picual' $\times$ 'Koroneiki' (Tables 1 and 2). A non-significant interaction between treatment (solarized and non-solarized soils) and crosses was generally found for growth measurements with only some exceptions for plant height in the first year. This lack of interaction indicates a positive effect of solarization on these characters independent of the origin of the seedlings. By the end of the experiment, seedlings from open polli- nation of 'Manzanilla de Sevilla', 'Picual' $x$ 'Koroneiki', and 'Arbequina' $\times$ 'Arbosana' showed a mean trunk diameter $21 \%, 4 \%$, and $1 \%$ thicker on solarized than non-solarized soils, respectively; however, the difference was not significant.

Flowering. Significant differences of the percentage of seedlings reaching AP between crosses were found the 2 years evaluated (Table 3). 'Arbequina' $\times$ 'Arbosana' provided a higher percentage of seedlings reaching AP followed by 'Manzanilla' open and 'Picual' $\times$
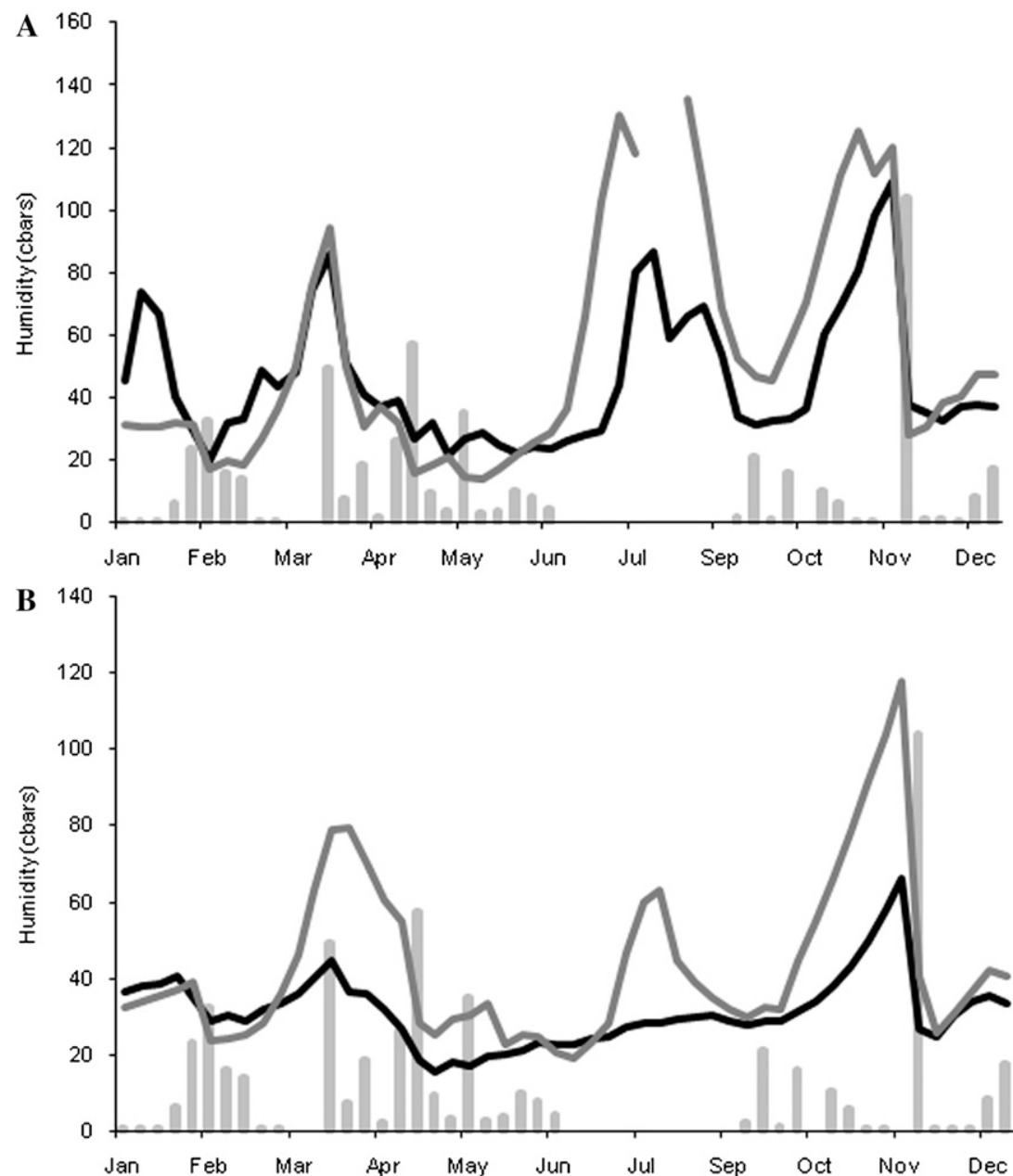

Fig. 2. Soil moisture in solarized (black) and in not solarized soils (gray) at 20-cm (up) and at 40-cm depth (down) in the first year of the experiment. Rainfall indicated in columns.

'Koroneiki', both in 2008 and 2009 (Table 3). The influence of the genitors on the duration of the JP has been previously reported in olive with 'Arbequina' considered one of the cultivars transmitting shorter average JP to its descendants (Santos-Antunes et al., 2005).

A significant interaction of cross $\times$ solarization was obtained on the percentage of seedlings reaching AP in 2009. Among the different crosses, the percentage of seedlings reaching AP in 'Manzanilla de Sevilla' open progeny was more than $50 \%$ higher in solarized than non-solarized soils (Fig. 3). The higher percentage of seedlings reaching AP in the solarized treatment of this progeny may be attributed to the larger diameter of the trees. The association between seedling trunk diameter and the ability to flower in these seedlings has been reported by SantosAntunes et al. (2005). The association between seedling growth and earliness of flowering has been widely reported in olive (MorenoAlías et al., 2010; Rallo et al., 2008) and in other fruit tree species (Janick and Moore, 1996).

Finally, solarization increased the flowering index of the different crosses $(P=0.0687$; Table 3 ) with a mean increase of $6 \%, 4 \%$, and $51 \%$ in 'Arbequina' $\times$ 'Arbosana', 'Manzanilla de Sevilla' open, and 'Picual' $\times$ 'Koroneiki', respectively (data not shown).

In conclusion, the results obtained here showed that soil solarization contributed to increase the number of seedlings reaching AP in some crosses in the first year of flowering, namely, in 'Manzanilla de Sevilla' open and 'Picual' $\times$ 'Koroneiki' progenies, the later flowering crosses in this experiment. This higher percentage of seedlings reaching AP appears to be related to the increased trunk diameter that may be caused by higher soil temperature in solarized soil with respect to non-solarized and to improved water status in the rhizosphere, which minimized water stress. A positive effect of solarization on flowering index was also observed. Thus, soil solarization could be useful as a tool for shortening the duration of the JP and fastening the progress of olive breeding programs, provided easy methodologies for the establishment of the plastic film in the orchard are available.

Table 1. Analysis of variance ( $P$ values) and mean values for trunk diameter $(\mathrm{mm})$ in olive progenies according to cross and solarization treatment.

\begin{tabular}{|c|c|c|c|c|c|c|c|c|}
\hline & \multicolumn{8}{|c|}{ Date } \\
\hline & July 2006 & Sept. 2006 & Nov. 2006 & Jan. 2007 & Mar. 2007 & May 2007 & Jan. 2008 & Jan. 2009 \\
\hline Crosses (A) & 0.0448 & 0.0221 & 0.0079 & 0.0171 & 0.0060 & 0.0122 & 0.0158 & 0.2904 \\
\hline \multicolumn{9}{|l|}{ Crosses (A) } \\
\hline 'Arbequina' X 'Arbosana' & $6.62 b^{z}$ & $8.07 \mathrm{~b}$ & $9.71 \mathrm{~B}$ & $10.20 \mathrm{~b}$ & $10.79 \mathrm{~B}$ & $12.41 \mathrm{~b}$ & $22.57 \mathrm{~b}$ & 45.72 \\
\hline 'Manzanilla' open & $7.20 \mathrm{a}$ & $9.25 \mathrm{a}$ & $11.10 \mathrm{~A}$ & $11.85 \mathrm{a}$ & $12.63 \mathrm{~A}$ & $14.40 \mathrm{a}$ & $27.91 \mathrm{a}$ & 49.80 \\
\hline Non-solarized & 6.66 & $8.40 \mathrm{~b}$ & $9.92 \mathrm{~b}$ & $10.51 \mathrm{~B}$ & $11.07 \mathrm{~B}$ & $12.70 \mathrm{~B}$ & 24.19 & 46.91 \\
\hline Solarized & 7.05 & $9.01 \mathrm{a}$ & $10.67 \mathrm{a}$ & $11.62 \mathrm{~A}$ & $12.30 \mathrm{~A}$ & $14.49 \mathrm{~A}$ & 26.30 & 50.71 \\
\hline
\end{tabular}

${ }^{\mathrm{z}}$ Mean separation in columns by Duncan's multiple range test at $P<0.05$ (lowercase letters) or 0.01 (uppercase letters). 
Table 2. Analysis of variance ( $P$ values) and mean values for plant height $(\mathrm{cm})$ in olive progenies according to cross and solarization treatment.

\begin{tabular}{|c|c|c|c|c|c|c|c|c|}
\hline & \multicolumn{8}{|c|}{ Date } \\
\hline & July 2006 & Sept. 2006 & Nov. 2006 & Jan. 2007 & Mar. 2007 & May 2007 & Jan. 2008 & Jan. 2009 \\
\hline Crosses (A) & 0.0003 & 0.0001 & 0.0001 & 0.0001 & 0.0001 & 0.0001 & 0.0001 & 0.0056 \\
\hline \multicolumn{9}{|l|}{ Crosses (A) } \\
\hline 'Arbequina' $\times$ 'Arbosana' & $100.7 \mathrm{~B}^{\mathrm{z}}$ & $123.2 \mathrm{~B}$ & $130.3 \mathrm{~B}$ & $132.4 \mathrm{~B}$ & $133.4 \mathrm{~B}$ & $140.8 \mathrm{~B}$ & $148.4 \mathrm{~B}$ & $202.5 \mathrm{~B}$ \\
\hline 'Manzanilla' open & 119.4 A & $150.3 \mathrm{~A}$ & $156.9 \mathrm{~A}$ & $161.0 \mathrm{~A}$ & $161.6 \mathrm{~A}$ & $170.3 \mathrm{~A}$ & $174.7 \mathrm{~A}$ & $231.4 \mathrm{~A}$ \\
\hline Non-solarized & 108.8 & 130.3 & 138.1 & 140.0 & 140.6 & 147.1 & 159.3 & 215.1 \\
\hline Solarized & 110.0 & 134.0 & 139.1 & 143.6 & 144.2 & 154.2 & 159.3 & 216.8 \\
\hline
\end{tabular}

${ }^{\mathrm{z}}$ Mean separation in columns by Duncan's multiple range test at $P<0.05$ (lowercase letters) or 0.01 (uppercase letters).

Table 3. Analysis of variance ( $P$ values) and mean values for percentage of seedlings reaching AP and flowering index in olive progenies according to cross and solarization treatment.

\begin{tabular}{|c|c|c|c|}
\hline & \multicolumn{2}{|c|}{ Seedlings reaching AP (\%) } & \multirow{2}{*}{$\begin{array}{c}\text { Flowering inde } \\
2009\end{array}$} \\
\hline & 2008 & 2009 & \\
\hline \multicolumn{4}{|l|}{ Source of variation } \\
\hline Crosses (A) & 0.0013 & 0.0034 & 0.5841 \\
\hline Solarization (B) & 0.1145 & 0.2122 & 0.0687 \\
\hline $\mathrm{A} \times \mathrm{B}$ & 0.3633 & 0.0350 & 0.1795 \\
\hline \multicolumn{4}{|l|}{ Crosses (A) } \\
\hline 'Arbequina' $\times$ 'Arbosana' & $21.84 \mathrm{~A}^{\mathrm{z}}$ & $77.17 \mathrm{~A}$ & 1.71 \\
\hline 'Manzanilla' open & $10.41 \mathrm{~B}$ & $61.66 \mathrm{~B}$ & 1.53 \\
\hline 'Picual' $\times$ 'Koroneiki' & $6.99 \mathrm{~B}$ & $48.25 \mathrm{~B}$ & 1.54 \\
\hline \multicolumn{4}{|l|}{ Solarization (B) } \\
\hline Non-solarized & 10.12 & 58.95 & 1.46 \\
\hline Solarized & 16.05 & 65.78 & 1.72 \\
\hline
\end{tabular}

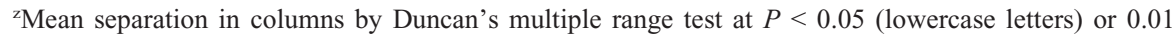
(uppercase letters).

$\mathrm{AP}=$ adult phase.

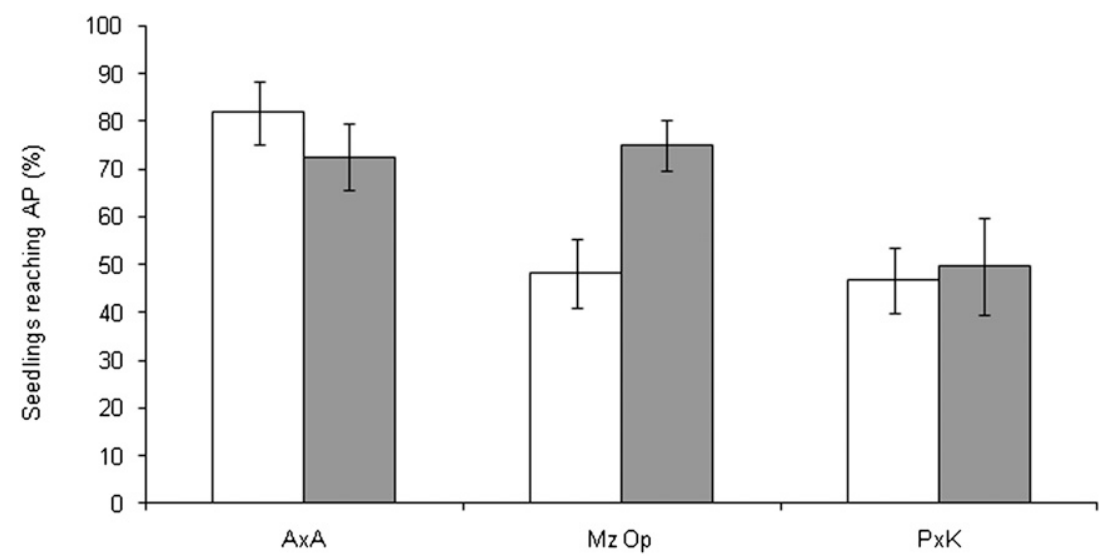

Fig. 3. Percentage of seedlings reaching adult phase in 2009 by cross $(\mathrm{A} \times \mathrm{A}=$ 'Arbequina' $\times$ 'Arbosana'; $\mathrm{Mz} \mathrm{Op}=$ 'Manzanilla de Sevilla' open pollination; $\mathrm{P} \times \mathrm{K}=$ 'Picual' $\times$ 'Koroneiki') in solarized (gray) and non-solarized (white) soils. Different letters indicate significant difference $(P<0.05)$. Error bars represent mean $\pm \mathrm{SE}$.

\section{Literature Cited}

Bagnall, D.J. 1992. Control of flowering in Arabidopsis thaliana by light, vernalization and gibberellins. Aust. J. Plant Physiol. 129:401-409.

Barranco, D. and L. Rallo. 2006. Mejora genética del olivo, p. 475-494. In: Llácer, G., M.J. Díez, J.M. Carillo and M.L. Badenes (eds.). Mejora genética de la calidad en plantas. Sociedad Española de Ciencias Hortícolas, Sociedad Española de Genética, Universidad Politécninca de Valencia, Valencia, Spain.

Bellini, E. 1993. Behaviour of some genetic characters in olive seedlings obtained by crossbreeding. Acta Hort. 317:197-208.
Janick, J. and J.N. Moore. 1996. Fruit breeding. Wiley, New York, NY.

Katan, J. 1987. Soil solarization, p. 77-105. In: Chet, I. (ed.). Innovative approaches to plant disease management. Wiley, New York, NY.

Lavee, S., N. Avidan, A. Haskal, and A. Ogrodovich. 1996. Juvenility period reduction in olive seedlings: A tool for enhancement of breeding. Olivae 60:33-41.

Moreno-Alías, I., H.F. Rapoport, R. López, L. León, and R. De la Rosa. 2010. Optimizing early flowering and pre-selection for short juvenile period in olive seedlings. HortScience 45:519-522.

Raj, H. and S.D. Sharma. 2009. Integration of soil solarization and chemical sterilization with beneficial microorganisms for the control of white root rot and growth of nursery apple. Sci. Hort. 119:126-131.

Rallo, P., R. Jiménez, J. Ordovás, and M.P. Suárez. 2008. Possible early selection of short juvenile period olive plants based on seedling traits. Aust. J. Agr. Res. 59:933-940.

Santos-Antunes, F. 1999. Acortamiento del periodo juvenil en olivo mediante técnicas de forzado de crecimiento y elección de genitores. $\mathrm{PhD}$ thesis, University of Córdoba, Córdoba, Spain.

Santos-Antunes, F., L. León, R. De la Rosa, J. Alvarado, A. Mohedo, I. Trujillo, and L. Rallo. 2005. The length of the juvenile period in olive as influenced by vigor of the seedlings and the precocity of the parents. HortScience 40:12131215 .

Stapleton, J.J. and J.E. DeVay. 1982. Effect of soil solarization on populations of selected soilborne microorganisms and growth of deciduous fruit tree seedlings. Phytopathology 72:323-326.

Stapleton, J.J., L. Ferguson, M.V. McKenry, D.S. Dougherty, and S.C. Stapleton. 1998. Using solarization to disinfest soil for olive nursery production. Acta Hort. 474:589-594.

Stapleton, J.J. and J.G. Garza-Lopez. 1988. Mulching of soils with transparent (solarization) and black polyethylene films to increase growth of annual and perennial crops in south-western Mexico. Trop. Agr. (Trinidad) 65:29-33.

Stapleton, J.J., E.J. Paplomatas, R.J. Wakeman, and J.E. DeVay. 1993. Establishment of apricot and almond trees using soil mulching with transparent (solarization) and black polyethylene film: Effects on verticillium wilt and tree health. Plant Pathol. 42:333-338.

Stapleton, J.J., J. Quick, and J.E. DeVay. 1985. Soil solarization: Effects on soil properties, crop fertilization and plant growth. Soil Biol. Biochem. 17:369-373.

Visser, T. 1970. The relation between growth, juvenile period and fruiting of apple seedlings and its use to improve breeding efficiency. Euphytica 19:293-302.

Zimmerman, R.H. 1973. Juvenility and flowering in fruit trees. Acta Hort. 34:139-142. 